\title{
Papers
}

\section{Helicobacter pylori infection and early onset myocardial infarction: case-control and sibling pairs study}

John Danesh, Linda Youngman, Sarah Clark, Sarah Parish, Richard Peto, Rory Collins for the International Studies of Infarct Survival (ISIS) Collaborative Group

\begin{abstract}
Objectives To examine the association between coronary heart disease and chronic Helicobacter pylori infection.

Design Case-control study of myocardial infarction at young ages and study of sibling pairs with one member affected and the other not.

Setting United Kingdom.

Participants 1122 survivors of suspected acute myocardial infarction at ages 30-49 (mean age 44 years) and 1122 age and sex matched controls with no history of coronary heart disease; 510 age and sex matched pairs of siblings (mean age 59 years) in which one sibling had survived myocardial infarction and one had no history of coronary heart disease. Main outcome measures Serological evidence of chronic infection with $H$ pylori.

Results 472 (42\%) of the 1122 cases with early onset myocardial infarction were seropositive for $H$ pylor $i$ antibodies compared with 272 (24\%) of the 1122 age and sex matched controls, giving an odds ratio of 2.28 (99\% confidence interval 1.80 to 2.90 ). This odds ratio fell to 1.87 (1.42 to $2.47 ; \mathrm{P}<0.0001$ ) after smoking and indicators of socioeconomic status were adjusted for and to 1.75 (1.29 to 2.36) after additional adjustment for blood lipid concentrations and obesity. Only 158 of the 510 pairs of siblings were discordant for $H$ pylori status; among these, 91 cases and 67 controls were seropositive (odds ratio 1.33 (0.86 to 2.05)). No strong correlations were observed between $H$ pylori seropositivity and measurements of other risk factors for coronary heart disease (plasma lipids, fibrinogen, $\mathrm{C}$ reactive protein, albumin, etc).

Conclusion In the context of results from other relevant studies, these two studies suggest a moderate association between coronary heart disease and $H$ pylori seropositivity that cannot be fully accounted for by other risk factors. But even if this association is causal and largely reversible by eradication of chronic infection, very large randomised trials would be needed to show this.
\end{abstract}

\section{Introduction}

By 1998, more than 25 epidemiological studies had reported on the association between Helicobacter pylori seropositivity and vascular disease, including nine studies that reported on a total of about 2000 cases of non-fatal myocardial infarction or death from coronary heart disease. ${ }^{12}$ In aggregate, these published reports indicated a weakly positive association, leading to suggestions that $H$ pylori infection might be an avoidable cause of coronary heart disease. But there is substantial heterogeneity among the findings of these nine studies of coronary heart disease $\left(\chi_{8}^{2}=53\right.$; $\mathrm{P}<0.0001$ ), with reports of strong associations with coronary heart disease in smaller studies generally not confirmed by larger and better designed studies (odds ratio 2.28 in studies of $<200$ cases $v 1.07$ in studies of $\geqslant 200$ cases; $\left.\chi_{1}^{2}=5.5 ; \mathrm{P}<0.05\right)$. Four of the nine studies were prospective, with a weighted mean age at coronary heart disease event of 66 years. These prospective studies should be more reliable than the retrospective studies since, in addition to their general advantages (such as minimisation of bias in casecontrol studies), they included larger numbers of cases (total of 1441) and better adjustment for standard risk factors and markers of socioeconomic status. There was no evidence of heterogeneity among them $\left(\chi_{3}^{2}=2.4 ; \mathrm{P}>0.1\right)$, and a combined analysis yielded a risk ratio of 1.15 (99\% confidence interval 0.91 to $1.45)^{2}$

Although this meta-analysis of prospective studies argues against a strong association between $H$ pylori infection and coronary heart disease, it cannot reliably confirm or exclude a moderate association. Studies of patients with early onset coronary heart disease may help to determine whether such an association exists since vascular risk factors (such as smoking, blood cholesterol, and blood pressure ${ }^{3}$ ) are often more strongly related to disease at younger ages. We report two complementary studies, one comparing young patients with acute myocardial infarction with young controls (which should maximise the strength of any association) and one comparing people with myocardial infarction at any age with an unaffected sibling (which should minimise any artefactual association due to confounding factors).

\section{Participants and methods}

Cases and controls

Patients with suspected acute myocardial infarction were randomised within 24 hours of the onset of \begin{tabular}{l} 
Clinical Trial \\
Service Unit and \\
Epidemiological \\
Studies Unit, \\
Nuffield \\
Department of \\
Clinical Medicine, \\
University of \\
Oxford, Radclife \\
Infirmary, Oxford \\
OX2 6HE \\
John Danesh \\
Merton College junior \\
research fellow \\
Linda Youngman \\
senior research fellow \\
Sarah Clark \\
research fellow \\
Sarah Parish \\
senior research fellow \\
Richard Peto \\
professor of medical \\
statistics and \\
epidemiology \\
Rory Collins \\
British Heart \\
Foundation professor \\
of medicine and \\
epidemiology \\
Correspondence to: \\
J Danesh \\
john.danesh@ \\
balliol.ox.ac.uk \\
BMJ 1999;319:1157-62 \\
Collaborators and \\
participating \\
centres are listed \\
on the BMJ's \\
website \\
extra \\
\hline wrw.bmj.com \\
\\
\end{tabular}

www.bmj.com 
symptoms in the third international study of infarct survival (ISIS-3) ${ }^{5}$ trial of fibrinolytic and antithrombotic treatments; in the United Kingdom, an epidemiological questionnaire was sent to them a few months later. ${ }^{3}$ Respondents were asked to provide contact details for their siblings and children aged over 30 living in the United Kingdom so that similar questionnaires could be sent to them, with an additional copy for their spouses; 21703 (47\%) of 46441 such relatives and 13577 of their spouses completed the questionnaire, with 30126 respondents denying any history of coronary heart disease. Patients with a history of stroke, gastrointestinal bleeding, or peptic ulceration tended not to be recruited into the ISIS-3 trial because of the treatments being evaluated, so people who reported such conditions were not eligible for the present studies: this excluded $1900(6 \%)$ relatives or spouses without a history of coronary heart disease. A further 13 were excluded because they provided insufficient information, leaving 28213 potential controls.

For this case-control study, the questionnaire was posted to 2670 patients aged $30-49$ at presentation with suspected myocardial infarction, of whom 56 were found to have died and 1920 (73\% of presumed survivors) completed it; 183 (9\%) were excluded because of a history of stroke, gastrointestinal bleeding, or ulcer, and a further 11 had insufficient information, leaving 1726 eligible cases. For the study among sibling pairs, patients aged 30-79 at presentation with suspected acute myocardial infarction who completed the questionnaire were eligible if they had a sibling of the same sex and similar age (within 5 years) who reported no history of coronary heart disease. Where a case had more than one such sibling, then the sibling closest in age with a blood sample available was chosen as the control.

\section{Questionnaires}

Controls were asked about their current body size, education, medical history, and consumption of cigarettes and alcohol, whereas cases were asked about their habits and history just before their index myocardial infarction (because having a heart attack may alter behaviour). ${ }^{3}$ Reported indicators of socioeconomic status included smoking, age ended full time education, number of live siblings, and height (with the last two regarded as markers of childhood crowding and nutritional deprivation ${ }^{6}$ respectively). Household income was estimated from the current postcode by using computer software that has been found to produce reasonably high correlations $(R=0.40$; $\mathrm{P}<0.0001)$ with self reported income. ${ }^{7}$ The birth rank of participants was estimated from the ages of their living siblings, since it has been suggested that having older siblings predisposes to earlier acquisition of $H$ pylori $^{8}$

\section{Blood samples}

Blood was collected into $10 \mathrm{ml}$ vacutainers containing $0.12 \mathrm{ml}$ preservative ( $15 \%$ potassium EDTA with 0.34 $\mathrm{mmol} / \mathrm{l}$ aprotinin). Samples were obtained from cases immediately after randomisation (within 24 hours of symptoms) but before the ISIS-3 trial treatments began. After returning the study questionnaire, potential controls were sent identical vacutainers for blood collection by their general practitioner. Whole blood samples were received by post in the central laboratory after a mean of two days and centrifuged, with plasma and buffy coat aliquots stored at $-40^{\circ} \mathrm{C}$.

Blood was obtained from 1593 (92\%) of the 1726 eligible early onset cases but from only 12053 (43\%) of the 28213 potential controls of any age, including only $6734(41 \%)$ of the 16604 potential controls aged 30-49. A further 470 cases and 404 controls were excluded because they had fewer than five stored plasma aliquots or their blood sample had been in the post for more than four days. This left 1123 (184 female and 939 male) eligible cases, and we selected at random 1123 controls matched for sex and age in five year bands from among the 6330 eligible controls aged 30-49, but tests for $H$ pylori serology failed in one case and one control. A total of 510 eligible sibling pairs had blood samples available. As 72 of these cases and 46 of these controls were also included in the casecontrol study of early onset myocardial infarction, subsidiary analyses were conducted after they had been excluded.

\section{Laboratory methods}

We measured H pylori specific IgG titres in previously unthawed plasma samples, blind to case-control status, by enzyme linked immunosorbent assay (ELISA; Orion, Espoo, Finland) using the manufacturer's pre-specified cut off for seropositivity (titre $\geqslant 300$ ). The intra-assay and interassay coefficients of variation for manufacturer's standards were $2 \%$ and $3 \%$ respectively. The reproducibility of $H$ pylori serology within individuals was determined (in order to assess regression dilution ${ }^{9}$ ) in blood samples taken three years apart from 1065 controls (of whom 115 were in the study of early onset myocardial infarction). We used Beckman CX-4 and CX-5 autoanalysers to measure cholesterol and albumin concentrations (both with Beckman reagents) and apolipoprotein $\mathrm{A}_{1}$ and $\mathrm{B}$ concentrations (Immuno reagents). Fibrinogen was measured with a Nephelometer Analyzer II (Behring reagents). The intra-assay and interassay coefficients of variation were $2 \%$ and $3 \%$ for both cholesterol and albumin and 2\% and $6 \%$ for both apolipoproteins and fibrinogen.

\section{Statistical methods}

We analysed the case-control study of early onset myocardial infarction using unmatched stratified logistic regression fitted by unconditional maximum likelihood and the sibling pair study using matched analyses and conditional maximum likelihood. Explanatory variables in the main adjusted analyses included age, sex, current cigarette smoking habit, age ended full time education, estimated household income, reported height, and geographical region of residence. (Subsidiary analyses included adjustment for blood lipid concentrations and obesity, but these factors were not strongly associated with $\mathrm{H}$ pylori serology in this study or in a synthesis of previous studies. ${ }^{11}$ ) Controls who were brothers or sisters of cases had, on average, more siblings than the cases, and so the analyses were standardised for the number of living siblings. ${ }^{10}$ Non-fasting blood total cholesterol, apolipoprotein $\mathrm{A}_{1}$ and $\mathrm{B}$, albumin, fibrinogen, and $\mathrm{C}$ reactive protein concentrations were also investigated as possible correlates of $\mathrm{H}$ pylori seropositivity. Odds ratios are given with $99 \%$ 
confidence intervals to allow for their exploratory nature, and two sided probability values are used.

\section{Results}

Case-control study of suspected myocardial infarction at ages $30-49$

Table 1 shows the characteristics of cases and their age and sex matched controls. As expected, known vascular risk factors (such as smoking and blood lipids) differed significantly between cases and controls. In all, 472 $(42 \%)$ of the cases were seropositive for $H$ pylori antibodies compared with $272(24 \%)$ of the controls (table 2). This difference yielded an odds ratio of 2.28 (99\% confidence interval 1.80 to 2.90 ), which fell to 1.87 (1.42 to 2.47) after smoking and indicators of socioeconomic status were adjusted for and to 1.75 (1.29 to 2.36) after additional adjustment for blood lipids and obesity. Varying the cut off titre for seropositivity did not materially alter the estimate, and the association did not seem to differ with age (table 2) or birth order (data not shown).

\section{Sibling pair study of suspected myocardial infarction at ages 30-79}

Matching cases of suspected myocardial infarction (mean age 59) with siblings of the same sex and similar age resulted in less extreme differences between cases and controls in various markers of socioeconomic status (table 3). The differences in some vascular risk factors (for example, current smoking, blood cholesterol concentration) also seemed smaller, perhaps because of the older average age of the sibling pairs as well as the matching. But discordance in H pylori seropositivity among the 510 sibling pairs was uncommon; only 91 seropositive cases had seronegative control siblings and 67 seronegative cases had seropositive controls (table 4). The ratio of these numbers of discordant pairs gave an odds ratio of 1.33 (99\% confidence interval 0.86 to 2.05 ), which was not much altered by adjustment for smoking and indicators of socioeconomic status $(1.37 ; 0.87$ to 2.15$)$ or by additional adjustment for blood lipids and obesity (1.29; 0.78 to 2.13$)$. When attention was restricted to the 420 pairs in which neither was included as a case or a control in the study of early onset myocardial infarction, 75 seropositive cases had seronegative control siblings and 54 seronegative cases had seropositive controls, again giving an odds ratio of 1.30 (0.81 to 2.11) that was largely unchanged by adjustments for smoking and indicators of socioeconomic status (1.34; 0.81 to 2.20 )
Table 1 Characteristics of survivors of acute myocardial infarction aged 30-49 and of age and sex matched controls. Values are mean (SD) unless stated otherwise

\begin{tabular}{llll} 
Characteristic & $\begin{array}{c}\text { Cases } \\
(\mathbf{n}=1122)\end{array}$ & $\begin{array}{c}\text { Controls } \\
(\mathbf{n}=1122)\end{array}$ & P value \\
\hline Questionnaire & $43.9(4.2)$ & $43.5(4.2)$ & Matched \\
\hline Age (years) & $939(83.6)$ & $939(83.6)$ & Matched \\
\hline No $(\%)$ of men & $27.5(4.4)$ & $25.8(3.2)$ & $<0.0001$ \\
\hline Body mass index $\left(\mathrm{kg} / \mathrm{m}^{2}\right)$ & $1.70(0.09)$ & $1.72(0.08)$ & $<0.0001$ \\
\hline Height $(\mathrm{m})$ & $79.8(14.7)$ & $76.3(11.9)$ & $<0.0001$ \\
\hline Weight $(\mathrm{kg})$ & $753(67)$ & $314(28)$ & $<0.0001$ \\
\hline No $(\%)$ of current smokers & $45(4)$ & $12(1)$ & $<0.0001$ \\
\hline No $(\%)$ with treated diabetes & $198(18)$ & $91(8)$ & $<0.0001$ \\
\hline No $(\%)$ with treated hypertension & $721(64)$ & $501(45)$ & $<0.0001$ \\
\hline No $(\%)$ ended education $<16$ years & $308(27)$ & $138(12)$ & $<0.0001$ \\
\hline No $(\%)$ with household income $<£ 12000 /$ /year & & & \\
\hline Blood sample & $5.88(1.20)$ & $5.32(0.99)$ & $<0.0001$ \\
\hline Total cholesterol $(\mathrm{mmol} / \mathrm{l})$ & $1.13(0.21)$ & $1.19(0.19)$ & $<0.0001$ \\
\hline Apolipoprotein $\mathrm{A}_{1}(\mathrm{~g} / \mathrm{l})$ & $1.20(0.30)$ & $1.00(0.24)$ & $<0.0001$ \\
\hline Apolipoprotein B $(\mathrm{g} / \mathrm{l})$ & $3.46(0.75)$ & $3.03(0.60)$ & $<0.0001$ \\
\hline Fibrinogen $(\mathrm{g} / \mathrm{l})^{*}$ & $2.31(0.50)$ & $1.99(0.34)$ & $<0.0001$ \\
\hline Log $10 \mathrm{C}$ reactive protein $(\mathrm{mg} / \mathrm{l}) \dagger$ & & \\
\hline
\end{tabular}

${ }^{*}$ Measurements were available for only 874 cases and 904 controls.

†Measurements were available for only 384 cases and 384 controls.

\section{Persistence of $\mathrm{H}$ pylori seropositivity and} correlations with other characteristics

Of 430 participants who were $H$ pylori seropositive at first testing, $411(96 \%)$ remained so three years later, and $628(99 \%)$ of 635 participants remained seronegative. There were no clearly significant differences between the mean concentrations of blood total cholesterol, apolipoproteins, fibrinogen, $\mathrm{C}$ reactive protein, or albumin or of alcohol consumption among $H$ pylori seropositive and seronegative individuals in the two studies (table 5). This is consistent with the results of a meta-analysis of 18 studies with information on 10000 people. ${ }^{11}$ Consequently, adjustment for these factors would not be expected to alter materially any association between $H$ pylori and myocardial infarction, and it did not do so.

\section{Discussion}

Previous studies have not provided convincing epidemiological evidence for or against a causal association between $H$ pylori infection and coronary heart disease, largely because they were limited by small sample sizes and incomplete adjustment for potential confounders. ${ }^{12}$ Our studies are comparatively large, adding more than 1600 cases of myocardial infarction to the aggregate of 2000 cases of non-fatal myocardial infarction or death from coronary heart disease available previously. Moreover, they involve many cases at young ages (when associations

Table 2 Odds of non-fatal myocardial infarction in people aged 30-49 who were $H$ pylori seropositive relative to those who were seronegative

\begin{tabular}{|c|c|c|c|c|}
\hline \multirow[b]{2}{*}{ Age (years) } & \multicolumn{2}{|c|}{ No (\%) seropositive } & \multicolumn{2}{|c|}{ Odds ratio ( $99 \%$ confidence interval) } \\
\hline & Cases & Controls* & Unadjusted & Adjustedt \\
\hline $30-39$ & $65 / 173(38)$ & $36 / 173(21)$ & 2.30 (1.22 to 4.32$)$ & 2.08 (0.97 to 4.45$)$ \\
\hline $40-49$ & $407 / 949(43)$ & $236 / 949(25)$ & 2.28 (1.76 to 2.95$)$ & 1.88 (1.40 to 2.53 ) \\
\hline All $(30-49)$ & $472 / 1122(42)$ & $272 / 1122(24)$ & $2.28(1.80$ to 2.90$)$ & 1.87 (1.42 to 2.47$)$ \\
\hline & & & $\chi_{1}^{2}=79(\mathrm{P}<0.0001)$ & $\chi_{1}^{2}=35(P<0.0001)$ \\
\hline
\end{tabular}

* Matched for sex and age in 5 year bands. †Adjustment was made for current cigarette smoking status, age ended full time education, estimated household income, region of residence, number of living siblings, and height. 
Table 3 Study of 510 sibling pairs: characteristics of survivors of acute myocardial infarction aged 30-79 and of their sex and age matched control siblings with no history of coronary heart disease. Values are mean (SD) unless stated otherwise

\begin{tabular}{lccc} 
Characteristic & $\begin{array}{c}\text { Cases } \\
(\mathbf{n}=\mathbf{5 1 0})\end{array}$ & $\begin{array}{c}\text { Controls } \\
(\mathbf{n}=\mathbf{5 1 0})\end{array}$ & P value \\
\hline Questionnaire & $59.4(9.6)$ & $58.9(9.8)$ & Matched \\
\hline Age (years) & $329(65)$ & $329(65)$ & Matched \\
\hline No $(\%)$ of men & $26.8(3.8)$ & $26.2(3.4)$ & 0.007 \\
\hline Body mass index $\left(\mathrm{kg} / \mathrm{m}^{2}\right)$ & $1.67(0.09)$ & $1.67(0.09)$ & 0.48 \\
\hline Height $(\mathrm{m})$ & $74.7(12.5)$ & $73.4(12.6)$ & 0.09 \\
\hline Weight $(\mathrm{kg})$ & $220(43)$ & $139(27)$ & $<0.0001$ \\
\hline No $(\%)$ of current smokers & $30(6)$ & $22(4)$ & 0.25 \\
\hline No $(\%)$ with treated diabetes & $155(30)$ & $114(22)$ & 0.003 \\
\hline No $(\%)$ with treated hypertension & $392(77)$ & $385(75)$ & 0.69 \\
\hline No $(\%)$ ended education $<16$ years & $115(25)$ & $98(21)$ & 0.12 \\
\hline No $(\%)$ with household income $<£ 12000 /$ yeart & & & \\
\hline Blood sample & $5.95(1.21)$ & $5.80(1.02)$ & 0.04 \\
\hline Total cholesterol $(\mathrm{mmol} / \mathrm{l})$ & $1.15(0.19)$ & $1.22(0.20)$ & $<0.0001$ \\
\hline Apolipoprotein $\mathrm{A}_{1}(\mathrm{~g} / \mathrm{l})$ & $1.19(0.29)$ & $1.10(0.23)$ & $<0.0001$ \\
\hline Apolipoprotein B $(\mathrm{g} / \mathrm{l})$ & $3.71(0.87)$ & $3.42(0.64)$ & $<0.0001$ \\
\hline Fibrinogen $(\mathrm{g} / \mathrm{l}){ }^{*}$ &
\end{tabular}

*Measurements were available for only 236 cases and 177 controls.

tInformation available for 456 cases and 468 controls.

Table 4 Odds of non-fatal myocardial infarction in siblings who were $H$ pylori seropositive relative to those who were seronegative

\begin{tabular}{lcccc}
$\begin{array}{l}\text { Serology status } \\
\text { (case/sibling control) }\end{array}$ & $\begin{array}{c}\text { No of sibling } \\
\text { pairs }^{*}\end{array}$ & \multicolumn{2}{c}{ Odds ratio (99\% confidence interval) } \\
\cline { 1 - 1 }$+/-$ & 91 & & Unadjusted & Adjustedt \\
\hline$-/+$ & 67 & & $\begin{array}{c}1.33(0.86 \text { to } 2.05) \\
\chi_{1}^{2}=2.8\end{array}$ & $\begin{array}{c}1.37(0.87 \text { to } 2.15) \\
\chi_{1}^{2}=3.1\end{array}$ \\
\hline$+/+$ & 173 & & \\
\hline$-/-$ & 179 & &
\end{tabular}

*Controls matched for sex and age in 5 year bands.

†Adjusted for current cigarette smoking status, age ended full time education, estimated household income, region of residence, and height.

with other risk factors are generally stronger) and include adjustment for several potential confounding factors. The results of both our studies are consistent with a moderate association between $H$ pylori seropositivity and coronary heart disease, particularly at younger ages.

\section{Strengths and limitations of case-control study} Some factors in our case-control study of early myocardial infarction could have led to underestimation of the role of $H$ pylori. Firstly, almost half of the controls were siblings or children of someone who had survived a myocardial infarction (although they were not necessarily relatives of the cases in the study). As $H$ pylori is often spread within families during childhood, ${ }^{12}$ if infection has a role in coronary heart disease relatives of survivors of myocardial infarction would have greater risks of carrying the infection than would the general population. The effects of any such "overmatching" would not be large, however, and the $24 \%$ H pylori seroprevalence in the controls is about that expected in the British population aged 30-49. ${ }^{13}$

Secondly, although high serum concentrations of IgG antibody to $H$ pylori are reliable indicators of chronic gastric infection ${ }^{14}$ and generally persist indefinitely from early life (without specific treatment), slight underestimation could result from inaccuracies in serological assays and from fluctuations of $H$ pylori titres within individuals over time. Substantial measurement errors were unlikely, however, as our assay method was accurate and samples taken three years apart showed good reproducibility for $H$ pylor $i$ status.

Thirdly, we included cases who had only "suspected" acute myocardial infarction on admission. However, three quarters of these suspected cases were subsequently confirmed and the remainder would probably have had some acute coronary syndrome. Moreover, the odds ratio was unchanged when analysis was restricted to the 842 cases who had myocardial infarction confirmed by electrocardiography or measurement of cardiac enzymes. Exclusion of cases who died before reaching hospital is also unlikely to have introduced material bias, as early mortality after infarction in people younger than 50 is relatively low, and there is no obvious reason to expect it to be strongly related. ${ }^{15}$ Finally, exclusion of cases with any history of gastrointestinal bleeding or peptic ulceration (both of which could be caused by certain cytotoxic strains of H pylori $^{16{ }^{17}}$ ) would not have caused any underestimation as controls who reported these conditions were also excluded.

Conversely, other factors could have led to overestimation of the role of $\mathrm{H}$ pylor $\mathrm{i}$ in coronary heart disease. Additional cardiological investigation in seropositive individuals because of upper gastrointestinal symptoms was unlikely, especially since dyspepsia was reported by identical percentages of seropositive $(36 \%)$ and seronegative cases (36\%). Most of the cases who completed the study questionnaire provided blood samples, but only half the potential controls did so. If those controls who provided blood, and so were included in the case-control comparisons, differed from those who did not in a way that was related both to risk of coronary heart disease and to $H$ pylori infection-for example, overrepresentation of higher social classes ${ }^{13}$ - this might have produced exaggerated results. For the study results to be explained entirely by differences in social class, however, all cases would have

Table 5 Mean (SD) levels of risk factors and other characteristics according to $H$ pylori seropositivity in cases and controls

\begin{tabular}{|c|c|c|c|c|c|}
\hline & \multicolumn{2}{|c|}{ Cases } & \multicolumn{2}{|c|}{ Controls } & \multirow{2}{*}{$\begin{array}{c}\text { Mean (SE) difference } \\
\text { between seropositive and } \\
\text { seronegative } \ddagger\end{array}$} \\
\hline & $\begin{array}{c}\text { Seropositive } \\
(\mathrm{n}=709)\end{array}$ & $\begin{array}{c}\text { Seronegative } \\
(\mathrm{n}=851)\end{array}$ & $\begin{array}{c}\text { Seropositive } \\
(\mathrm{n}=501)\end{array}$ & $\begin{array}{c}\text { Seronegative } \\
(n=1086)\end{array}$ & \\
\hline Total cholesterol $(\mathrm{mmol} / \mathrm{l})$ & $5.90(1.20)$ & $5.88(1.18)$ & $5.62(0.99)$ & $5.39(1.03)$ & $0.070(0.042)$ \\
\hline Apolipoprotein $A_{1}(g / l)$ & $1.13(0.20)$ & $1.14(0.21)$ & $1.21(0.19)$ & $1.19(0.19)$ & $-0.005(0.007)$ \\
\hline Apolipoprotein B (g/l) & $1.20(0.29)$ & $1.19(0.30)$ & $1.07(0.23)$ & $1.02(0.24)$ & $0.020(0.010)$ \\
\hline Fibrinogen $(\mathrm{g} / \mathrm{l})^{*}$ & $3.55(0.79)$ & $3.50(0.79)$ & $3.18(0.63)$ & $3.06(0.62)$ & $0.030(0.033)$ \\
\hline $\log _{10} \mathrm{C}$ reactive protein $(\mathrm{mg} / \mathrm{l}) \dagger$ & $2.34(0.49)$ & $2.29(0.50)$ & $2.00(0.32)$ & $1.99(0.34)$ & $0.027(0.034)$ \\
\hline Albumin $(\mathrm{g} / \mathrm{l})$ & $38.2(3.70)$ & $38.8(3.57)$ & $40.2(3.1)$ & $40.8(3.4)$ & $-0.22(0.13)$ \\
\hline Units of alcohol/week in drinkers & $26(26)$ & $26(26)$ & $22(22)$ & $21(20)$ & $2.0(1.1)$ \\
\hline
\end{tabular}

*Measurements were available for only 1050 cases and 1049 controls. †Measurements were available for only 384 cases and 384 controls. łMean (SE) among seropositive minus mean among seronegative adjusted by multiple regression for age, sex, and case or control status. 
to have come from the lowest two social classes and all controls from the top two (assuming seroprevalences based on other studies ${ }^{13}$ of $40 \%$ and $20 \%$ at these two extremes). Such gross selection bias is implausible, and, moreover, the estimated mean household incomes of potentially eligible controls who provided blood samples and of those who did not were similar (£19 $600 v £ 18$ 800). Nevertheless, some residual confounding is suggested by the reduction in the odds ratio from $2.28\left(\chi_{1}^{2}=79\right)$ to $1.87\left(\chi_{1}^{2}=35\right)$ after smoking and some imperfect indicators of socioeconomic status were adjusted for. The fact that such crude adjustment reduced the odds ratio so substantially suggests that exact adjustment for all confounders would have produced an even greater reduction, but such considerations are difficult to quantify.

\section{Strengths and limitations of sibling pair study}

Studying sibling pairs should provide better matching for socioeconomic status and should also help avoid selection biases. But, as $69 \%$ of the pairs had the same $H$ pylori status (which is similar to the $60 \%$ concordance rate reported among several hundred non-identical Swedish twins ${ }^{18}$ ), only 158 pairs were discordant and hence informative about any association with myocardial infarction. The odds ratio of seropositivity for myocardial infarction was $1.33 \quad(99 \%$ confidence interval 0.86 to 2.05) and was largely unchanged after adjustment. This suggests that exact adjustment for the truly relevant factors would have little effect. Although this odds ratio is not significant, it is compatible with the results of our study of early onset myocardial infarction and published prospective studies (figure).

\section{Conclusions}

Ever since the early claims of strong associations, the evidence for an association between $H$ pylori and coronary heart disease has steadily weakened. Our findings - together with a meta-analysis of previous reports-renew the possibility of a moderate association, particularly in early middle age, but exclude the existence of a strong one. Hence, unless epidemiological studies of $H$ pylori subtypes (or of other infective agents) give more extreme relative risks, randomised trials of anti-infective interventions may be needed to help determine causality. Even if a causal link exists, any effect of infection on risk of coronary heart disease might not be rapidly and fully reversible (as is the case

\section{Key messages}

- Most previous studies of associations between chronic H pylori infection and coronary heart disease have been too small or prone to bias

- This case-control study found myocardial infarction was twice as common in people infected with $H$ pylori as in those not infected

- Among sibling pairs, myocardial infarction was about a third more common in seropositive people than those who were seronegative

- These results support a weak association between $H$ pylori infection and coronary heart disease

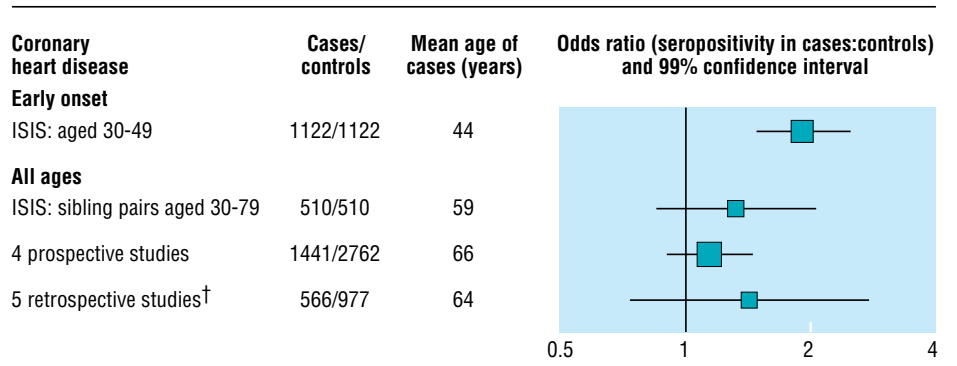

TThree other retrospective studies are not included since they did not report separate results for cases of myocardial infarction. Together these studies included fewer than 150 cases of myocardial infarction.

Odds ratios in epidemiological studies of $H$ pylori seropositivity and death from coronary heart disease or myocardial infarction. Details of studies and methods of analysis are available elsewhere. ${ }^{12}$ Black squares indicate odds ratio, with area of square proportional to number of cases, and horizontal lines represent confidence intervals

with other risk factor interventions $\left.{ }^{19}\right)$. Hence, trials of interventions against infection might need to randomise large numbers of participants and to observe them for several years to assess reliably any effects on coronary heart disease.

We thank the patients and their relatives who participated in the ISIS studies, their general practitioners, and the medical and nursing staff from the participating hospitals in the United Kingdom; Peter Froggatt, Cheryl Swann, and Robert Waller of the Independent Scientific Committee on Smoking and Health, Department of Health; and Stewart Cederholm-Williams and Julian Marshall of Oxford Bio-Research Laboratory.

Contributors: RC, RP, SP, and LY established the ISIS epidemiological database. JD helped with $H$ pylori serum antibody measurements, analysed the data, and drafted the manuscript. SC performed laboratory measurements. All authors edited the manuscript. Jill Barton and Kathy Jayne coordinated questionnaire data collection. Deanne Lloyd, Buki Chukwurah, Janet Taylor, and Joy Hill helped with laboratory measurements Alison Palmer and Paul Appleby helped with data analysis and computing. JD is the study guarantor.

Funding:JD is supported by Merton College and a Frohlich award, and RC holds a British Heart Foundation professorship. The ISIS trials and epidemiological studies were supported by the manufacturers of the study drugs ${ }^{5}$ and by the British Heart Foundation, Medical Research Council, Imperial Cancer Research Fund, and Tobacco Products Research Trust of the Independent Scientific Committee on Smoking and Health, Department of Health.

Competing interests: None declared.

1 Danesh J, Collins R, Peto R. Chronic infections and coronary heart disease: is there a link? Lancet 1997;350:430-6.

2 Danesh J, Appleby P. Persistent infection and vascular disease: a systematic review. Expert Opin Invest Drugs 1998;7:691-713.

3 Parish S, Collins R, Peto R, Youngman L, Barton J, Jayne K, et al. Cigarette smoking tar yields, and non-fatal myocardial infarction: 14000 cases and 32000 controls in the United Kingdom. BMJ 1995;311:471-7.

4 Prospective Studies Collaboration. Cholesterol, diastolic blood pressure, and stroke: 13000 strokes in 450000 people in 45 prospective cohorts. Lancet 1995;346:1647-53.

5 ISIS-3 (Third International Study of Infarct Survival) Collaborative Group. ISIS-3: a randomised comparison of streptokinase vs tissue plasminogen activator vs anistreplase and of aspirin plus heparin vs aspirin alone among 41229 cases of suspected acute myocardial infarction. Lancet 1992;339:753-70.

6 Yarnell JWG, Limb ES, Layzell JM, Baker IA. Height: a risk marker for ischaemic heart disease. Eur Heart J 1992;13:1602-5.

7 Danesh J, Semmence J, Gault S, Appleby P, Peto R. Postcodes as useful markers of social class: population-based study in 26000 British households. BMJ 1999;318:843-5.

8 Blaser MJ, Chyou PH, Nomura A. Age at establishment of Helicobacter pylori infection and gastric carcinoma, gastric ulcer, and duodenal ulcer risk. Cancer Res 1995;55:562-5.

9 MacMahon S, Peto R, Cutler J, Collins R, Sorlie P, Neaton J, et al. Blood pressure, stroke, and coronary heart disease-part 1. Prolonged differences in blood pressure: prospective observational studies corrected for the regression dilution bias. Lancet 1990;335:765-74

10 Mendall MA, Goggin PM, Molineaux N, Levy J, Toosy T, Strachan D, et al. Childhood living conditions and Helicobacter pylori seropositivity in adult life. Lancet 1992;339:896-7. 
11 Danesh J, Peto R. Risk factors for coronary heart disease and infection with Helicobacter pylori: meta-analysis of 18 studies. BMJ 1998;316:1130-2.

12 Goodman KJ, Correa P. The transmission of Helicobacter pylori. A critical review of the evidence. Int J Epidemiol 1995;24:875-87.

13 Sitas F, Forman D, Yarnell JWG, Burr ML, Elwood PC, Pedley S, et al. Helicobacter pylori infection rates in relation to age and social class in a population of Welsh men. Gut 1991;32:25-8.

14 Feldman RA, Evans SJW. Accuracy of diagnostic methods used for epidemiological studies of Helicobacter pylori. Aliment Pharmacol Ther 1995;9(suppl 2):21-31.

15 Sonke GS, Beaglehole R, Stewart AW, Jackson R, Stewart FM. Sex differences in case fatality before and after admission to hospital after acute cardiac events: analysis of community based coronary heart disease register. $B M J 1996 ; 313: 853-5$.
16 Crabtree JE, Taylor JD, Wyatt JI, Heatley RV, Shallcross TM, Tompkins DS, et al. Mucosal IgA recognition of Helicobacter pylori 120KDa protein, peptic ulceration, and gastric pathology. Lancet 1991;338:332-5.

17 Pasceri V, Cammarota G, Patti G, Cucoc L, Gasbarrini A, Grillo RL, et al. Association of virulent Helicobacter pylori strains with ischemic heart disease. Circulation 1998;97:1675-9.

18 Malaty HM, Engstrand L, Pedersen NL, Graham DY. Helicobacter pylori: genetic and environmental influences. A study of twins. Ann Intern Med 1994;120:982-6.

19 Collins R, Peto R, Gray R, Parish S. Large-scale randomized evidence: trials and overviews. In: Weatherall D, Ledingham JGG, Warrell DA, eds. Oxford textbook of medicine. Oxford: Oxford University Press, 1996:21-32.

(Accepted 29 July 1999)

\title{
Economic transition and changing relation between income inequality and mortality in Taiwan: regression analysis
}

\author{
Tung-liang Chiang
}

\section{Institute of Health \\ Policy and \\ Management, \\ College of Public \\ Health, National \\ Taiwan University, \\ Taipei 10018, \\ Taiwan \\ Tung-liang Chiang professor \\ tlchiang@ha.mc. ntu.edu.tw}

BMJ 1999;319:1162-5

\begin{abstract}
Objective To examine the changing relation between income inequality and mortality through different stages of economic development in Taiwan.

Design Regression analysis of mortality on income inequality for three index years: 1976, 1985, and 1995. Setting 21 counties and cities in Taiwan.

Main outcome measures All age mortality and age specific mortality in children under age 5 .

Results When median household disposable income was controlled for, the association between income inequality and mortality became stronger in 1995 than in 1976. Especially, the association between income inequality and mortality in children aged under 5 , with adjustment for differences in median household disposable income, changed from non-significant in 1976 to highly significant in 1995 . In 1995, the level of household income after adjustment for income distribution no longer had a bearing on mortality in children under 5 .

Conclusion The health of the population is affected more by relative income than by absolute income after a country has changed from a developing to a developed economy.
\end{abstract}

\section{Introduction}

Does relative income become more important than absolute income in determining population health

\begin{tabular}{|c|c|c|c|c|}
\hline Variable & 1953 & 1976 & 1985 & 1995 \\
\hline \multicolumn{5}{|l|}{ Socioeconomic indicators } \\
\hline Population (million) & 8.3 & 16.5 & 19.3 & 21.3 \\
\hline Population aged $\geqslant 65(\%)$ & 2.5 & 3.6 & 5.1 & 7.6 \\
\hline Gross national product per capita (US\$) & $196^{*}$ & 1132 & 3297 & 12396 \\
\hline Gini coefficient & 0.56 & 0.28 & 0.29 & 0.32 \\
\hline Ratio of highest fifth's income to lowest fifth's & 20.46 & 4.18 & 4.50 & 5.34 \\
\hline \multicolumn{5}{|l|}{ Health indicators } \\
\hline Crude death rate (per 1000) & 9.4 & 4.7 & 4.8 & 5.6 \\
\hline Under 5s mortality (per 1000)† & 21.1 & 3.9 & 2.1 & 1.9 \\
\hline \multicolumn{5}{|l|}{ Life expectancy (years): } \\
\hline Male & 58.2 & 68.7 & 70.8 & 71.9 \\
\hline Female & 61.4 & 73.6 & 75.8 & 77.8 \\
\hline
\end{tabular}

after a country has changed from a developing to a developed economy? By comparing countries that are members of the Organisation for Economic Cooperation and Development, Wilkinson showed that: (a) a strong relation exists between life expectancy and income distribution, whereas its relation with gross national product per capita is weak; and (b) a decrease in the prevalence of relative poverty is significantly related to a rapid improvement in life expectancy. ${ }^{12}$ Kaplan et $\mathrm{al}^{3}$ and Kennedy et $\mathrm{al}^{4}$ reported independently that in the United States the relation between income distribution and mortality remained highly significant even after controlling for absolute income. Nevertheless, most of the studies on population health and relative income versus absolute income are cross sectional studies that were done in post-industrialised countries where the epidemiological transition is complete. I aimed to examine the changing relation between income inequality and mortality through different stages of economic development in Taiwan, using data at county and city level.

Taiwan, with a population of 21.3 million in 1995 , is a newly industrialised country; its achievement in economic development has been frequently termed an "economic miracle" (table 1). In the early 1950s, Taiwan was a poor country with a gross national product per capita of no more than US $\$ 200$ ( $£ 72$ valued at 1950 s prices). ${ }^{5}$ Since 1953 a series of economic development plans has been effectively implemented, and Taiwan's economy has shifted from agricultural to industrial and from import oriented to export oriented. ${ }^{6}$ As a result, gross national product per capita has increased rapidly to US\$1132 ( $£ 627$ valued at 1976 prices) in 1976 and to US\$12 396 ( $£ 7853$ valued at 1995 prices) in $1995 .^{5}$

The economic development of Taiwan has been identified not only with rapid growth but also with improved income distribution. ${ }^{7}$ Like most developing countries Taiwan had a large income gap in the early years of economic transition. The ratio of income share of the richest $20 \%$ to that of the poorest $20 \%$ in Taiwan reached 20.5 in 1953, but it decreased substantially to 4.2 in 1976 and then slightly increased to 5.3 in $1995 .{ }^{5}$ Similarly, the Gini coefficient-a commonly used measure of the degree of income inequality, ranging from zero to a maximum of one-for Taiwan has decreased 